\title{
Implementation of Omotenashi in Japanese Ryokan
}

\author{
Wahyu Nur Wijayanti ${ }^{1}$, Akhmad Saifudin ${ }^{2}$
}

Universitas Dian Nuswantoro, Semarang, Jawa Tengah, Indonesia

Universitas Dian Nuswantoro, Semarang, Jawa Tengah, Indonesia

\begin{tabular}{|c|c|}
\hline Article History & Abstract \\
\hline $\begin{array}{l}\text { Submitted date: } \\
\text { 2021-05-20 } \\
\text { Accepted date: } \\
\text { 2021-05-24 } \\
\text { Published date: } \\
\text { 2021-05-31 }\end{array}$ & $\begin{array}{l}\text { Omotenashi, often referred to as Japanese hospitality, is a service to customers based } \\
\text { on Japanese spirit and culture. Omotenashi is evident in the services provided by a } \\
\text { ryokan, which is a traditional Japanese inn. This paper seeks to describe the application } \\
\text { of omotenashi in ryokan management, how omotenashi control is implemented, and } \\
\text { what the implementations are. The research was conducted by observing the }\end{array}$ \\
\hline $\begin{array}{l}\text { Keywords: } \\
\text { omotenashi; hospitality; } \\
\text { ryokan; Japanese culture }\end{array}$ & $\begin{array}{l}\text { involvement of the Hyoe Koyokaku ryokan, an old ryokan located in the tourist area of } \\
\text { Arima Onsen. From the results of observations and analysis, it was found that ryokan } \\
\text { employees control omotenashi as a vision of service to customers through training, } \\
\text { instruction, and improvement based on feedback. The implementation of ometenashi } \\
\text { is manifested in personalization, host-guest relationships, hospitableness, and lots of } \\
\text { little surprises. }\end{array}$ \\
\hline
\end{tabular}

\section{Kata Kunci:}

omotenashi; hospitality; ryokan; budaya Jepang

\section{Abstrak}

Implementasi Omotenashi di Penginapan Tradisional Jepang

Omotenashi atau sering disebut sebagai Japanese hospitality adalah pelayanan kepada customer yang berdasarkan spirit dan budaya Jepang. Omotenashi secara nyata nampak dalam layanan yang diberikan oleh ryokan, yaitu penginapan tradisional Jepang. Tulisan ini berupaya mendeskripsikan penerapan omotenashi dalam pengelolaan ryokan, bagaimana manajemen omotenashi diterapkan dan apa saja implementasinya. Penelitian dilakukan dengan cara observasi terlibat di ryokan Hyoe Koyokaku, sebuah ryokan tua yang berlokasi di di daerah wisata Arima Onsen. Dari hasil observasi dan analisis ditemukan bahwa omotenashi sebagai visi pelayanan kepada customer dikuasai oleh para pegawai ryokan dengan cara pelatihan, instruksi, dan perbaikan berdasarkan feedback. Implementasi ometenashi diwujudkan dalam personalization; host guest relationship; hospitableness dan lots of little surprises.

Corresponding author:

1 312201300459@mhs.dinus.ac.id

2 akhmad.saifudin@dsn.dinus.ac.id 


\section{Pendahuluan}

Jepang merupakan negara destinasi wisata yang selain terkenal dengan keindahan lokasi wisata juga terkenal dengan layanan kepada wisatawan yang sempurna. Layanan ini disebut omotenashi yakni semacam hospitality (Hayashida, 2006; Ketut Surajaya, 2020; Yamagami, 2008b; Yi, 2016) dalam industri pariwisata. Meskipun arti sederhana dari omotenashi adalah "semangat keramahan Jepang," definisinya dapat mencakup empat aspek: (1) menjamu tamu, (2) mempersembahkan pesta atau resepsi, (3) memahami perilaku atau sikap orang, dan (4) perlakuan atau prosedur kegiatan tertentu. Lebih khusus lagi, etimologi istilah ini berasal dari "kontak yang jujur dengan orang lain" dan "membangun/menciptakan hubungan antarmanusia yang lebih baik" (Ikeda, 2013; Morishita, 2016).

Omotenashi dianggap sebagai konsep layanan yang dominan karena ia mengundang pengunjung, menawarkan mereka makan (dan terkadang hadiah), berkomunikasi dengan mereka, dan membuat mereka merasa nyaman dan diterima. Menurut Setogawa (2013), omotenashi dengan rela menerapkan pendekatan "untuk Anda" tanpa menerima tip seperti yang biasa terjadi di dunia Barat. Dasar omotenashi adalah layanan yang mengedepankan kesopanan (courtesy), kerendahan hati (modesty), dan layanan elegan (sophistication), yang dipupuk sebagai bagian dari sejarah dan budaya Jepang (Chen \& Kato, 2014; Okamoto \& Akahori, 2014). Dari sudut pandang manajemen layanan, Kobayashi (2015) mendefinisikan omotenashi sebagai layanan berkualitas tinggi yang dipengaruhi oleh sifat, budaya, sejarah, dan gaya hidup Jepang.

Kata omotenashi berasal dari kata motenasu 'melayani', penambahan prefiks \{o- $\}$ di awal kata merupakan penanda honorifik dalam bahasa Jepang. Verba motenasu yang berubah menjadi nomina yaitu motenashi mendapat prefix \{o-\} menjadi omotenashi. Kata ini sering digunakan pada frasa hito o motenasu yang artinya 'melayani atau menyambut seseorang'. Kata motenasu ini juga sering diartikan sebagai 'tidak membawa (memiliki) apapun' oleh masyarakat Jepang. Nakao dan Umeshitsu dalam Terasaka dan Inaba (2014) menyatakan bahwa omotenashi ini berarti proses menyenangkan mitra bicara dengan cara menempatkan diri di posisi mitra bicara tersebut sehingga mampu memahami kebutuhan ataupun kondisi mitra bicara. Dengan melakukan hal ini, kebutuhan mitra bicara dapat terpenuhi tanpa perlu bertanya terlebih dahulu. Orientasi omotenashi ini adalah kesempurnaan dalam pelayanan dengan usaha yang mendetail dan tanpa cela. Bahkan dapat dinyatakan bahwa tidak ada permintaan yang tidak dapat dikabulkan, serta kesempurnaan pelayanan yang diberikan bahkan diusahakan melampaui ekspektasi konsumen (Terasaka dan Inaba, 2014).

Meskipun omotenashi sering disamakan dengan hospitality, sebenarnya ada perbedaan yang sangat mendasar. Omotenashi dilandasi oleh spirit budaya orang Jepang dan hospitality cenderung sebagai sebuah strategi profesional untuk memuaskan dan menggaet customer. Di negara-negara Barat, istilah hospitality mengacu pada dua aspek, yakni (1) memberikan sambutan hangat dan kebaikan bagi wisatawan dan tamu; dan (2) memiliki daya reseptif dan kemampuan untuk menggaet wisatawan atau tamu. Berkenaan dengan omotenashi, aspek pertama serupa, sedangkan aspek kedua berbeda dalam beberapa hal. Menurut penelitian sebelumnya, hospitality dunia Barat tidak dapat sepenuhnya mengungkapkan arti sebenarnya dari omotenashi (Hattori, 2008), sementara beberapa penelitian telah menyimpulkan bahwa kedua istilah tersebut mencakup konsep yang sama (Shibuya, 2014; Yamagami, 2008a). Mengenai poin terakhir, meskipun omotenashi dan keramahtamahan mencakup konsep yang serupa, seperti perhatian tanpa pembayaran dan kemampuan untuk menanggapi situasi dan kebutuhan tamu, terdapat perbedaan besar: keramahtamahan di hotel-hotel Barat mencakup hubungan hierarkis antara tuan rumah dan tamu; omotenashi di Jepang mencakup hubungan yang setara antara tuan rumah dan tamu. 
Menurut Skandrani dan Kamoun (2014) omotenashi meliputi 4 dimensi kunci, yaitu: 1) Personalization, 2) Host Guest Relationship, 3) Hospitableness, dan 4) Lots of Little Surprises. Personalization adalah segala hal yang merupakan proses mengubah atau memodifikasi sesuatu yang tujuannya adalah untuk menemukan dan menentukan ciri khas atau jati diri. Kemudian yang kedua adalah membina hubungan yang harmonis, yang saling percaya, yang saling menguntungkan, yang saling menghargai antara host dan guest. Lalu Hospitableness atau keramahtamahan adalah kehendak atau keinginan yang tulus untuk menyenangkan, memenuhi kebutuhan, menghibur, membantu, ataupun segala hal yang membuat orang lain merasa nyaman dan senang. Terakhir adalah tindakan-tindakan kejutan, biasanya dalam bentuk hadiah yang ditujukan untuk memberi kesenangan yang lebih kepada para tamu.

Dalam dunia pariwisata di Jepang, omotenashi yang benar-benar nampak diimplementasikan adalah di ryokan. Ryokan adalah penginapan bergaya tradisional Jepang dan biasanya menawarkan pemandian air panas yang terkenal dengan nama onsen. Ryokan banyak terdapat di daerah-daerah yang masih terdapat bangunan bersejarah. Di ryokan ini para tamu dapat menikmati fasilitas washitsu (kamar ala Jepang) yang berlantaikan tatami (tikar Jepang), tidur menggunakan futon (kasur Jepang)), dan makan masakan set khas Jepang yang disebut kaiseki ryori, memakai yukata, serta yang paling terkenal adalah mandi atau berendam air panas alami di onsen.

Jika dibandingkan dengan hotel modern, ryokan memiliki karakteristik khas yang memungkinkan para tamu dapat menikmati suasana atau nuansa yang berbeda dengan kehidupan modern. Nuansa tersebut di antaranya adalah:

1. Unsur budaya tradisional Jepang yang sangat lekat, yang dapat membuat para tamu seperti dihipnotis dibawa ke suasana Jepang yang masih sangat tradisional;

2. Nilai sejarah, yang mana ryokan pada umumnya merupakan bangunan bersejarah sudah sangat tua;

3. Terdapat onsen yang dipercaya dapat menjadi obat berbagai penyakit.

Ryokan dan omotenashi merupakan objek kajian penelitian yang sangat menarik untuk dikaji. Keduanya bersifat khas Jepang dan tidak dimiliki oleh budaya lain. Keberadaan keduanya seolah menjadi anomali atau sesuatu yang bertentangan dengan sosok negara Jepang yang dikenal sebagai bangsa yang maju dan modern. Untuk itu dalam tulisan ini dikaji penerapan omotenashi dalam pengelolaan ryokan di Jepang.

Penelitian tentang ryokan pernah dilakukan oleh Matsukawa (2016) yang meneliti kondisi saat ini dan prospek ryokan di Jepang. Penelitian dilakukan di desa Yudanaka Shibu, kota Yamanao Uchi, perfektur Nagano. Hasil penelitian ini menunjukkan bahwa prospek ryokan berpotensi positif jika ditangani dengan baik dengan menggunakan manajemen omotenashi berdasarkan filosofi tradisional Jepang dan fasilitas fisik diperbaiki tanpa mengubah ciri tradional Jepang. Kemudian penelitian berikutnya tentang omotenashi dilakukan oleh Morishita (2016). Penelitian Morishita dilakukan di Kyusu, yakni di daerah wisata Kurokawa Onsen yang di situ terdapat banyak ryokan. Tujuan penelitian Morishita adalah untuk menentukan faktor kunci keberhasilan pengelolaan omotenashi di Kurokawa Onsen. Hasilnya menunjukkan bahwa agar para pegawai ryokan memahami dan menerapkan omotenashi diterapkan pelatihan-pelatihan untuk para pegawai Yunior oleh pegawai senior, namun pelatihan tersebut ternyata tanpa menggunakan manual yang terperinci. Di dalam penelitian yang pertama, Matsukawa meneliti berdasarkan angket dan wawancara para tamu, baik domestik maupun manca negara terkait prospek ryokan berdasarkan kondisi saat itu menurut penilian para tamu. Peneliti tidak mengkaji dari sudut pandang pengelola Ryokan. Sementara pada penelitian kedua, Morishita meneliti bagaimana keberlangsungan manajemen omotenashi yang dijalankan di ryokan-ryokan di Kurosawa Onsen. Dalam penelitian ini 
dikaji bagaimana omotenashi diterapkan secara konkrit oleh sebuah ryokan, baik layanan jasa maupun layanan fisiknya. Dengan kajian ini diharapkan kita dapat mempelajari bagaimana penginapan tradisional Jepang dikelola dan dapat menjadi daya tarik wisata dengan ryokan dan omotenashinya.

\section{Metode Penelitian}

Sumber data dalam penelitian ini berupa hasil observasi selama penulis melaksanakan program internship/magang yang diselenggarakan oleh Program Studi Sastra Jepang Fakultas Ilmu Budaya Universitas Dian Nuswantoro dari bulan Juli 2017 - Juli 2018 di Ryokan Hyoe Koyokoku Jepang yang terletak di daerah wisata alam Arima Onsen tepatnya 1904 Arimacho, Kita Ward, Kobe, Hyogo 6511401, Jepang, dan juga dari hasil wawancara dengan narasumber Masui Hitomi (67 tahun) yang merupakan HRD dan マナー教師 manaa kyoushi (guru manner) Ryokan Hyoe Koyokaku.

Data yang dianalisis pada penelitian ini adalah layanan fisik dan layanan jasa dari keempat dimensi kunci omotenashi yang diterapkan pada ryokan Hyoe Koyokaku, yaitu: personalization, host guest relationship, hospitableness, dan lots of litte suprises. Data dikumpulkan menggunakan teknik observasi dan wawancara. Observasi bertujuan memperoleh data yang lebih spesifik, dan dalam penelitian ini menggunakan teknik observasi terlibat. Observasi yang dilakukan selama menjalani program Internship di ryokan Hyoe Koyokaku. Penulis melakukan pendokumentasian hasil observasi dengan mencatat setiap kegiatan yang dilakukan di ryokan tersebut. Hasil observasi kemudian dikonfirmasikan kepada HRD Hyoe Koyokaku dan staf ryokan yang lain untuk memastikan kebenarannya. Selain itu penulis juga melakukan teknik wawancara kepada HRD ryokan Hyoe Koyokaku yang bernama Masui Hitomi (67 tahun) yang bertujuan untuk mengkonfirmasi kebenaran dari hasil observasi yang penulis lakukan. Hasil observasi dan wawancara ini menjadi data primer dalam penelitian ini. Sedangkan data sekunder yang penulis gunakan yaitu referensi dari web resmi, brosur, arsip ryokan Hyoe Koyokaku dan dari sumber lain.

Data yang berupa hasil pengamatan dan wawancara dengan narasumber dianalisis berdasarkan paradigma kualitatif dengan menggunakan teori 4 dimensi kunci omotenashi yang disebutkan oleh Skandrani dan Kamoun (2014:147).

\section{Hasil dan Pembahasan}

\subsection{Hasil Penelitian}

Dari hasil observasi juga dapat diketahui bahwa tamu yang menginap di ryokan ini akan menikmati layanan yang menjadi ciri khas dari ryokan, yaitu:

(1) Menikmati tampilan bagian depan bangunan ryokan yang menggunakan konsep bangunan kuno, menjadikan seolah-olah berada di Jepang 100 tahun lampau.

(2) Ketika masuk kamar, melepaskan alas kaki di genkan (pintu masuk) terlebih dahulu.

(3) Kamar di tata dengan gaya tradisional Jepang. Berlantaikan tatami (tikar jerami), yang ditenun dari serat tanaman keras. Jendelanya ditutup dengan kertas Jepang yang dipekatkan pada bingkai kayu atau shoji (layar kertas) bukan tirai. Pintunya dalam kamar juga ditutup dengan kertas.

(4) Tengah ruangan ada meja rendah dan beberapa zabuton (alas bantal). Di atas meja ada tatanan baki berisi ocha (teh Jepang).

(5) Kasur yang digunakan adalah kasur tradisional Jepang, yaitu dapat dilipat lalu disimpan ke dalam oshiire.

(6) Setiap kamar akan disediakan yukata (jubah tradisional Jepang) untuk pakaian tidur atau dapat digunakan selama menginap di ryokan. Yukata sifatnya bebas dipakai sampai keluar ke sekitar ryokan. 
(7) Di kamar, tamu dapat menyantap hidangan kaiseki (makanan khas Jepang) yang disebut heyashoku (makan di kamar). Tetapi juga boleh makan di restoran ala Jepang atau modern yang terdapat di ryokan tersebut.

(8) Di sudut ruang kamar terdapat rangkaian bunga khas Jepang yang disebut ikebana, lampu duduk khas Jepang, lampu utama ala Jepang mematikan menyalakan dengan cara ditarik, serta terdapat lukisan dinding dengan gambar khas Jepang.

(9) Selain terdapat ofuro (bak mandi untuk berendam) di dalam kamar, juga ada onsen dan rotenboru (bak mandi outdoor).

Dari hasil observasi terlibat dan interpretasi selama melakukan magang di ryokan Hyoe Koyokaku memang omotenashi diterapkan secara nyata dalam pengelolaan dan pelayanan ryokan. Pegawai baru, termasuk pemagang, diberikan pelatihan khusus bagaimana mengelola dan melayani tamu berdasarkan standard omotenashi ryokan Hyoe Koyokaku. Selain diberikan pelatihan para pegawai yunior juga mempelajari omotenashi dengan mencontoh seniornya ketika melayani tamu dan juga dengan melakukan instruksi seniornya ketika menemukan hal baru yang belum pernah diketahui penanganannya. Manajemen omotenashi yang diterapkan di ryokan ini jika digambarkan adalah sebagai berikut.

Gambar 1. Manajemen Omotenashi Ryokan

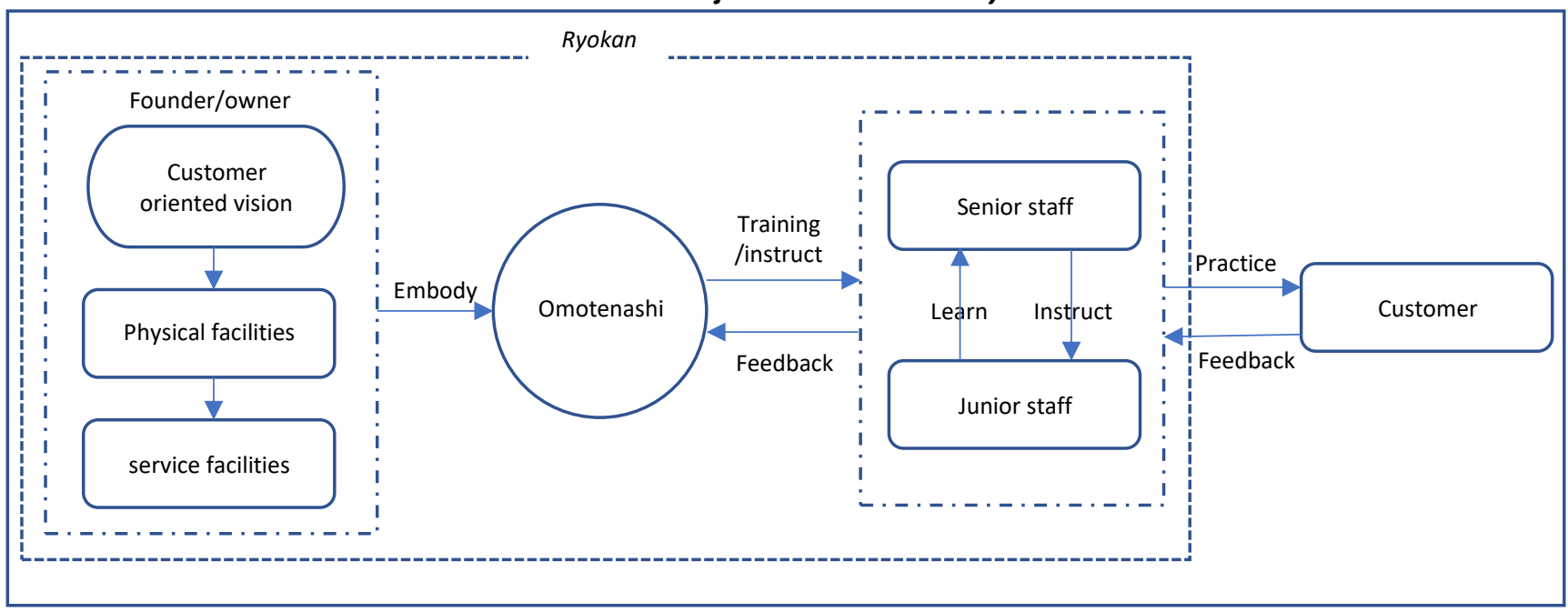

Ditemukan implementasi omotenashi yang diterapkan oleh ryokan Hyoe Koyokaku seperti tampak pada tabel berikut.

\begin{tabular}{ll}
\multicolumn{1}{c}{ Table 1. Implementasi Omotenashi } \\
\hline Jenis Layanan & Implementasi \\
\hline Personalization & $\begin{array}{l}\text { Musium kecil/galeri gambar, tulisan sejarah ryokan, benda-benda bersejarah yang } \\
\text { berkaitan dengan ryokan. }\end{array}$ \\
\hline$-\quad$ fisik & $\begin{array}{l}\text { Welcome drink makanan dan minuman khas ryokan, layanan penjelasan sejarah } \\
\text { ryokan }\end{array}$ \\
\hline$-\quad$ jasa & $\begin{array}{l}\text { Taiko no ashiyu (merendam kaki di kinshen 'onsen berwarna coklat untuk terapi } \\
\text { Host Guest Relationship }\end{array}$ \\
\hline$-\quad$ fisik & Heyashoku (layanan makan di kamar dengan dilayani oleh Nakaisan) \\
\hline$-\quad$ jasa & Baiten (toko yang menjual oleh-oleh produksi ryokan) \\
\hline Hospitableness & Omotenashi front office \\
\hline$-\quad$ fisik & \\
\hline$-\quad$ jasa & Pemberian hadiah momen-momen khusus \\
\hline$-\quad$ fisik &
\end{tabular}




\subsection{Pembahasan}

Pembahasan berikut mendeskripsikan hasil penelitian terkait dengan rumusan dan tujuan penelitian yang dianalisis menggunakan 4 dimensi kunci omotenashi. Setiap dimensinya terdapat 2 kelompok layanan, yaitu layanan fisik dan jasa.

\subsubsection{Personalization}

\subsubsection{Layanan Fisik (Galeri sejarah di ryokan Hyoe Koyokaku)}

Di dalam ryokan ada musium atau galeri yang berisi foto-foto, tulisan-tulisan mengenai sejarah ryokan Hyoe dan benda-benda bersejarah kuno yang dipakai Hyoe pada zaman dulu. Galeri ini terletak di higashikan (gedung timur) lantai 10. Setiap tamu yang menginap pasti ditawari untuk mengunjungi galeri tersebut. Mengapa demikian, istimewanya sejarah ryokan ini dikarenakan Toyotomi Hideyoshilah yang berperan menetapkan nama Hyoe tersebut. Perlu diketahui bahwa tidak semua penginapan di Jepang memiliki galeri yang seperti ini. Jadi dapat dikatakan bahwa keberadaan galeri ini menjadi ciri khas ryokan Hyoe Koyokaku yang dapat menjadi sarana mempertahankan identitasnya sebagai salah satu ryokan kuno di Jepang karena usianya yang sudah 700 tahun.

\section{Gambar 3. Galeri}

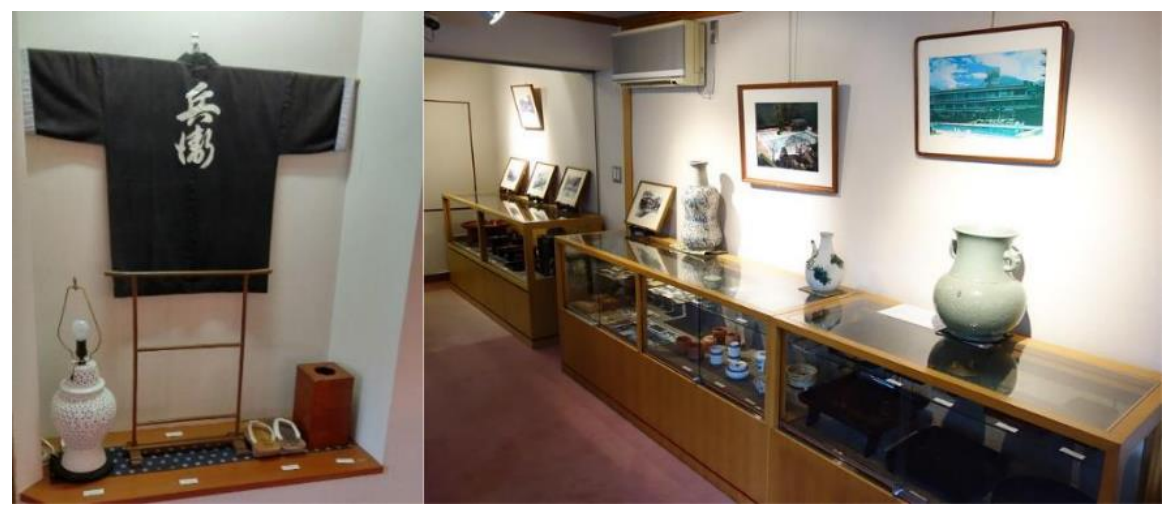

Di dalam gambar terdapat Samue (baju kerja bertuliskan Hyoe yang dikenakan para bantousan 'pegawai laki-laki ryokan') masih diabadikan sebagai tanda sejarah. Diabadikan juga lentera yang biasanya dibawa bantousan ketika keluar dari ryokan serta geta yang dipakai sebagai alas kaki. Peralatan untuk menjamu para tamu pada zaman dahulu masih tersimpan di dalam galeri ini juga, benda-benda bersejarah inilah yang menjadi saksi pertama kali berdirinya Hyoe. Dari beberapa contoh dokumentasi di dalam galeri yang penulis ambil, menunjukkan salah satu identitas yang paling terkenal dari ryokan ini. Dengan kata lain Ryokan Hyoe Koyokaku memiliki personalisasi yang kuat dari adanya sebuah sejarah yang mendalam, maka para tamu dapat tersentuh dengan omotenashi cerita sejarah yang tidak semua ryokan memilikinya.

\subsubsection{Layanan Jasa (Yugomori)}

Setiap tamu yang masuk kamar akan diberikan welcome drink ocha (teh Jepang) dan yugomori (kue berbentuk logo Hyoe Koyokaku) yaitu hyoutan 'labu air Jepang' 8 membentuk melingkar seperti bunga. Pemberian welcome drink ini merupakan hal yang standard dilakukan hotel-hotel di Jepang, namun menyajikan yugomori koyokaku berbentuk hyoutan melingkar hanya dilakukan di ryokan ini dan menjadi ciri khasnya. Tamu yang tertarik dengan bentuk kue ini pasti akan bertanya lebih lanjut mengenai filosofinya atau sejarahnya dan di sinilah kesempatan bagi staf ryokan untuk menceritakan sejarah simbol hyoutan tersebut. 
Gambar 4. Yugomori sebagai welcome drink

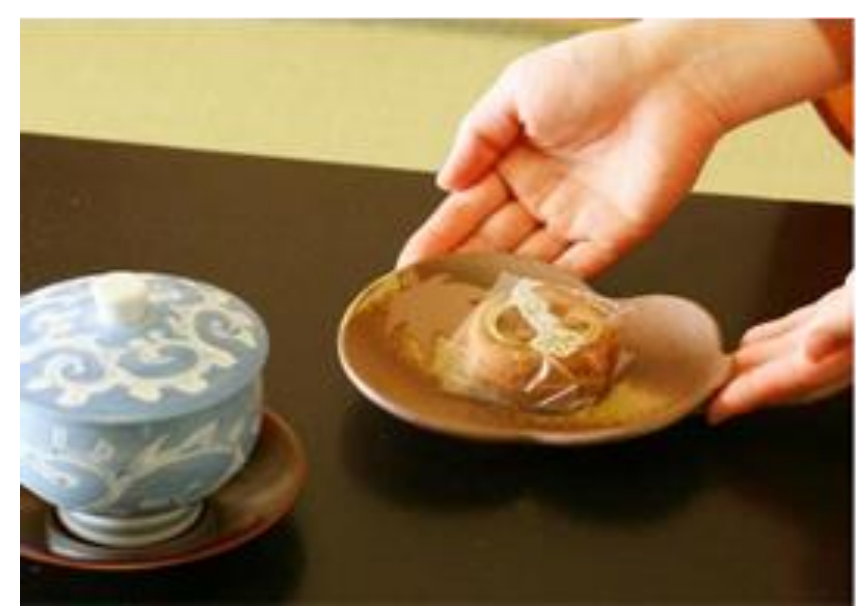

Welcome drink ini diberikan kepada tamu yang sudah memasuki kamarnya, kemudian nakaisan masuk ke kamar dengan membawa ocha dan yugomori tersebut. Nakaisan maupun bantousan dalam melayani para tamu dengan berpedoman pada hito koto "afureru egao de omotenashi" yakni moto yang artinya keramahtamahan dengan senyum yang meluap. Ini dapat diartikan sebagai pelayanan dengan berlandaskan omotenashi yang dilakukan dengan tulus ikhlas, penuh perhatian serta kasih sayang, yang diekspresikan dengan senyuman. Harapannya dapat memberikan kesan pertama yang baik kepada tamu.

\subsubsection{Host Guest Relationship}

\subsubsection{Layanan Fisik (Ashiyu)}

Di ryokan Hyoe Koyokaku ini tersedia fasillitas terapi kesehatan merendam kaki menggunakan kinsen. Fasilitas ini merupakan fasilitas standar yang juga disediakan ryokan dengan tujuan memberikan pelayanan sebaik-baiknya kepada tamu. Terapi ini terletak di lantai 9 gedung timur dan merupakan sarana outdoor sehingga para tamu dapat menikmati pemandangan pegunungan Rokko yang terkenal di kawasan wisata Arima Onsen, juga dapat menikmati keindahan alam di setiap musimnya.

Gambar 5. Ashiyu

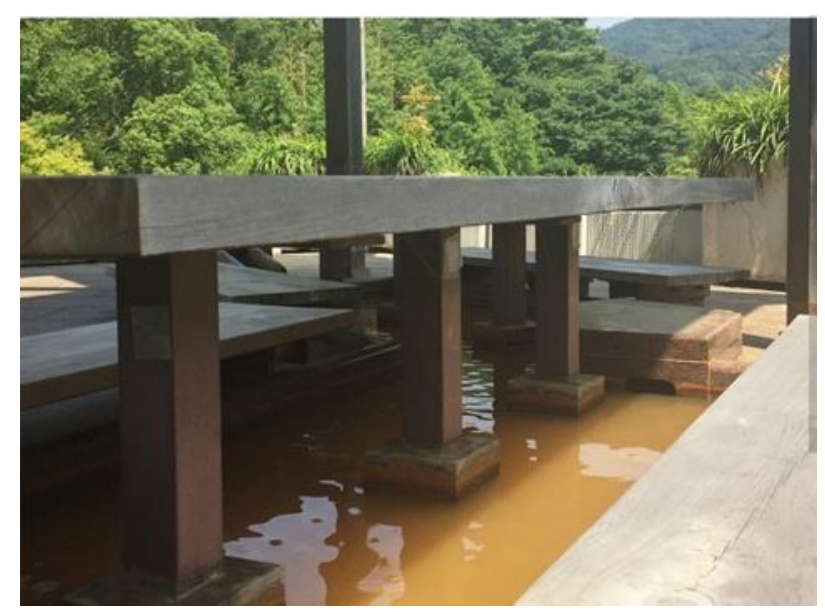

Tampak gambar 5 di atas bertepatan dengan musim gugur, para tamu dimanjakan dengan pemandangan alam yang indah, warna dedaunan berubah menjadi warna warni, sambil merendam 
kaki dalam kinsen, mata tertuju pada alam sekitar, membuat badan menjadi sehat, hati gembira, pikiran rileks kembali.

Berendam kaki ini menggunakan air kinsen selain dapat merelaksasi badan agar tetap hangat ketika cuaca dingin terlebih berkhasiat mengobati beberapa penyakit. Pelayanan ini bertujuan untuk memberikan fasilitas terapi kesehatan serta menjadi spot yang sangat mengasyikkan untuk berlibur. Merendam kaki di air kinsen sangat populer di kalangan penduduk Arima Onsen, mereka menyebutnya dengan "Taiko no Ashiyu".

\subsubsection{Layanan Jasa (Heyashoku)}

Istilah heyashoku dipakai di dunia penginapan tradisional Jepang, yang dimaksud dengan heyashoku adalah makan di kamar dilayani oleh nakaisan. Timing heyashoku ditentukan oleh pihak tamu. Pagi hari biasanya sekitar pukul 06:00-07:00, nakaisan sudah mempersiapkan hidangan untuk chooshoku 'sarapan'. Layanan jasa yang diberikan oleh pihak ryokan ketika heyashoku sebagai berikut: mengetuk pintu kamar dua kali terlebih dahulu sambil mengucapkan salam "shitsureiitashimasu 'permisi'". Jika ada jawaban "hai 'ya'", maka langsung membuka pintu disertai ucapan "ohayou gozaimasu 'Selamat Pagi"” (posisi masih di genkan). Setelah tamu menjawab "ohayou 'Pagi'", nakaisan bertanya lagi "haittemo yoroshideshouka 'Bolehkah saya masuk?'”. Tamu menjawab "hai 'Silakan'" maka nakaisan melepaskan geta di genkan, masuk dengan posisi duduk badan sedikit membungkuk lalu bertanya "futon o agettemo yoroshideshouka 'Apakah saya bisa membereskan futon?'”. Tamu menjawab "hai douzo 'Ya, silakan'”. Segera nakaisan membereskan semua futon yang ada di kamar, dilipat, dimasukan ke dalam oshiire. Meja pendek ditata di tengah ruangan lalu nakaisan meminta izin keluar untuk mengambil hidangan yang akan disajikan.

\section{Gambar 6. Heyashoku}

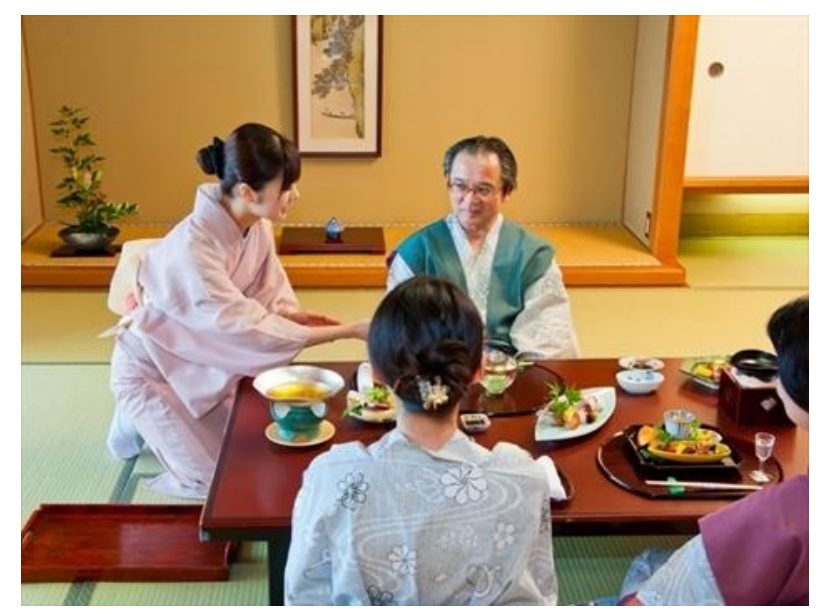

Nakaisan dengan wajah ceria menata hidangan di meja sambil menjelaskan menu yang dihidangkan saat itu. Setelah semua lengkap di meja, nakaisan boleh meninggalkan ruangan. Nakaisan selalu siaga di pantry, apabila sewaktu-waktu ada panggilan dari kamar tamu atau tamu sudah beranjak ke onsen maka segera untuk membereskan peralatan makan yang ada di kamar tersebut. Nakaisan diumpamakan sebagai tuan rumah ketika heyashoku dan pengunjung sebagai tamu, tidak boleh sedikitpun merasa tidak puas atau kecewa. Dengan omotenashi yang tulus melayani ketika heyashoku, tamu akan merasa senang dan puas dengan layanan jasa dari nakaisan, rasa dan penyajian dari hidangan tersebut juga mewakili dari sebuah omotenashi.

\subsubsection{Hospitableness}

\subsubsection{Layanan Fisik (Baiten)}


Baiten Hyoe Koyokaku terdapat di lantai 1 gedung selatan dekat dengan front office, lobby, coffee corner dan shopping center. Tempatnya yang sangat strategis membuat baiten ini selalu ramai pengunjung baik yang menginap, rapat, ataupun wisata sehari di ryokan ini. Selain menyediakan aneka oleh-oleh yang standar ryokan pada umumnya, Koyokaku menyediakan oleholeh khas Koyokaku sendiri maupun khas Arima Onsen. Menariknya lagi, Koyokaku memproduksi sendiri macam-macam oleh-oleh tersebut, agar tamu tidak hanya berkesan menginap saja akan tetapi dapat merasakan makanan khas Koyokaku, souvenir dan barang khas Koyokaku untuk kenang-kenangan, dan sake khas Koyokaku. Selain dinikmati tamu itu sendiri, juga biasanya dijadikan oleh-oleh yang diberikan kepada sanak handai taulannya. Menjadikan nilai kebanggaan tersendiri bagi tamu memberikan oleh-oleh khas Koyokaku. Di sini berarti secara tidak langsung memberitahukan dengan tersirat bahwa telah menginap di salah satu ryokan kuno bersejarah yang terkenal di Jepang.

Beraneka ragamnya oleh-oleh yang ada didisplay sehingga membuat tamu dapat menikmati belanja di situ. Baiten ini berhasil menjadi salah satu keramahtamahan layanan tempat berbelanja yang banyak diminati tamu.

Gambar 7. Baiten

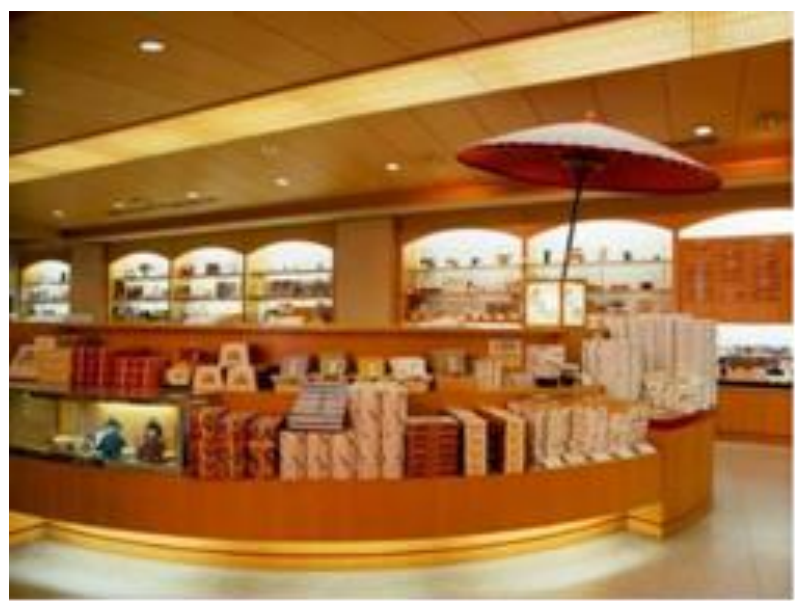

\subsubsection{Layanan Jasa (Omotenashi Front Office)}

Front office ryokan adalah tempat di mana tamu tiba dan pertama kali bertemu dengan seorang staf di ryokan tersebut. Posisi penting di ryokan adalah front office atau biasa disebut resepsionis, karena posisi ini akan selalu berhubungan dengan tamu. Sudah menjadi keharusan bahwa menjadi staff FO adalah seseorang yang ramah, good looking, memiliki senyum yang indah lagi tulus, dan memiliki empati yang tinggi. Maka penilaian pertama dari tamu mengenai omotenashi ryokan tersebut adalah baik dan mengesankan di hati para tamu.

Staf front office Hyoe Koyokaku diwajibkan memiliki kemampuan bahasa Jepang yang baik mengingat bahasa Jepang memiliki tingkatan keseponanan. Kemampuan bahasa Asing seperti bahasa Inggris juga wajib dimiliki. Agar dalam melayani tamu Internasional dan dapat memberikan kenyamanan kepada tamu secara bahasa. Untuk bahasa selain bahasa Jepang dan bahasa Inggris juga menjadi nilai plus untuk staf front office. Demi memberikan pelayanan prima kepada para tamu, ryokan ini memiliki staf dari berbagai negara yaitu Korea, China, Rusia, Taiwan dan negara lainnya. Dengan begitu apabila ada tamu dari tiap-tiap negara tersebut akan dilayani oleh staf tiap negaranya. Ini menjadi suatu nilai lebih untuk ryokan ini, karena tamu dapat leluasa berkomunikasi dengan menggunakan bahasanya sendiri, selain itu pasti tamu dari negara tersebut akan merasa senang dapat bertemu orang senegaranya di luar negeri. 
Pada saat penulis menjalani program internship, penulis juga ditugaskan oleh pimpinan ryokan untuk melayani tamu-tamu dari Indonesia. Pimpinan ryokan menginginkan layanan maksimal untuk tamu yang datang. Karena penulis berasal dari Indonesia, maka dengan melayani tamu yang berasal dari Indonesia, diharapkan dapat mengakomodasi permintaan tamu secara maksimal. Dengan menugaskan penulis, kendala bahasa dapat teratasi dan permintaan-permintaan khusus terutama yang terkait dengan hidangan halal (dikarenakan ada beberapa tamu Indonesia beragama Islam yang menghindari makanan yang mengandung babi dan minuman beralkohol) dapat terakomodasi. Menurut penulis ini merupakan pelayanan jasa yang unsur omotenashinya tinggi. Pimpinan ryokan bahkan menerima internship dari berbagai negara dengan tujuan membantu staf agar tamu-tamu dari luar negeri terakomodasi kebutuhannya tanpa terkendala bahasa, karena dilayani oleh staf dan pemagang yang berasal dari negara para tamu itu berasal.

\subsubsection{Lots of Littte Surprises}

\subsubsection{Layanan Fisik (Surprise untuk tamu pada momen khusus)}

Tamu yang berulang tahun diberi surprise kue ulang tahun, hadiah, chanchanko 'rompi', osekihan (beras merah), dan shanpan/supaakuringuwain 'minuman Champagne'. Namun ada juga hadiah spesial makanan khas Jepang harus memesan terlebih dahulu dan berbayar, seperti taikatsu dzukuri, taishioyaki, fune mori katsu dzukuri, dan ise ebi dzukuri. Surprise baik yang tidak berbayar maupun berbayar semua bertujuan untuk memberikan kejutan kepada yang berulang tahun agar merasa senang dan berkesan.

Untuk kue ulang tahun diberikan ketika makan malam baik pada saat heyashoku atau dinner di restoran. Sedangkan hadiah diberikan saat heyashoku malam atau saat tamu check out, sehingga menjadi surprise yang menyenangkan. Hadiah yang diberikan cukup beragam, namun semuanya diberikan simbol ryokan Hyoe Koyokaku. Dengan diberikannya surprise hadiah ini, diharapkan tamu mengenangnya dan menceritakan kepada teman/keluarganya yang lain. Ini dalam dunia marketing dapat menjadi mouth to mouth marketing atau pemasaran dari mulut ke mulut. Testimoni yang baik dari para tamu dapat menjadi media pemasaran yang efektif juga.

Dari berbagai macam surprise yang diberikan kepada tamu yang berulang tahun membuat tamu sangat senang dan pastinya terharu, merasa sangat diperhatikan dan diistimewakan di hari yang spesial. Momen yang sangat berbahagia tersebut pasti akan terus diingat dan dirindukan.

\section{SIMPULAN}

Tulisan ini telah memberikan gambaran tentang implementasi omotenashi yang diterapkan di ryokan Hyoe Koyokaku, yakni sebuah ryokan yang bereputasi bintang 5 di daerah wisata Arima Onsen. Ryokan ini telah dengan sungguh-sungguh menerapkan omotenashi dengan cara penerapan standard yang jelas dalam pemberian pemahaman dan penguasaan terhadap para pegawainya, dan dipraktikkan oleh pegawainya kepada para tamunya. Penerapan omotenashi ini dapat digambarkan dalam Gambar 1, yang sekaligus menjadi kontribusi tulisan dalam menggambarkan salah satu model penerapan manajemen omotenashi. Implementasi berdasarkan Skandrani dan Kamoun (2014) juga telah diterapkan di ryokan Hyoe Koyokaku melalui empat hal yang terdapat dalam omotenashi, yakni 1) Personalization, 2) Host Guest Relationship, 3) Hospitableness, dan 4) Lots of Little Surprises. Dari hasil penelitian ini kami berharap dapat memberikan manfaat, khususnya kepada para pelaku atau penyelenggara wisata dan peminat serta peneliti wisata sebagai wawasan ataupun dasar pengembangan untuk pengembangan dan perbaikan, maupun penelitian dalam bidang wisata.

\section{REFERENSI}

Chen, J., \& Kato, S. (2014). Is omotenashi interpreted hospitality in English? Asahi University 
Management, 28, 21-31.

Hattori, K. (2008). Introduction of hospitality (2nd ed.). Maruzen.

Hayashida, M. (2006). Text of Hospitality, Heartfelt Omotenashi for Impressing the Guest. Asa Publisher.

Ikeda, N. (2013). Omotenashi: Japanese hospitality as the global standard. In Management of Service Businesses in Japan. Books.Google.com.

Ketut Surajaya, I. (2020). Omotenashi and Tri Hita Karana in Perspectives of Ethic, Culture and History. In International Journal of Innovative Science and Research Technology (Vol. 5, Issue 1). www.ijisrt.com

Kobayashi, K. (2015). Scientific approach to omotenashi. Quality, 45, 6-11.

Matsukawa, Y. (2016). 日本旅館の現状と存続ため一考察 一長野県湯田中渋温泉郷を例に一 (Nihon ryokan no genjyou to sonzoku tame-kousatsu -Naganoken Yudanaka Shibu Onsen Kyou o rei ni- ). Tokai University.

Morishita, S. (2016). Managing omotenashi in onsen ryokans. Journal of Global Tourism Research, 1(2), 157-160. https://doi.org/10.37020/jgtr.1.2_157

Okamoto, M., \& Akahori, T. (2014). Kindness isn't any technique, the foundation of omotenashi is "Culture." Human Development, 26, 32-35.

Setogawa, R. (2013). The Toughness and Common Features in Omotenashi Styled Managing Companies. Development Engineering, 33, 23-28.

Shibuya, Y. (2014). Reason of high performance for omotenashi management company. Shogyo-Kai, 67, 114-116.

Skandrani, H., \& Kamoun, M. (2014). Hospitality Meanings and Consequences Among Hotels Employees and Guests. In Tourists' Perceptions and Assessments Advances in Culture, Tourism and Hospitality Research (Issue August, pp. 147-156).

Terasaka, K., \& Inaba, Y. (2014). Hospitaliti to omotenashi, sabisu no hikaku bunseki. The Journal of Social Science, 85-120.

Yamagami, T. (2008a). Deepening of hospitality spirit. Houritsu-Bunka-sha.

Yamagami, T. (2008b). Evolution of the Spirit Omotenashi for Creating the Omotenashi Culture. Houritsu-Bunka-sha.

Yi, Z. (2016). Introducing Omotenashi to the World: Challenges to Japanese Customer Service in a Cross-cultural Setting. Transcultural Management Review, 13(12), 47-63. https://core.ac.uk/download/pdf/87199635.pdf

https://hyoe.co.jp/ Web resmi Ryokan Hyoe Koyokaku, Jepang 